\title{
A New Evaluation Index System of Water Scarcity Degree and Prediction Model Based on Grey Theory \\ Yiheng Bian
}

North China Electric Power University,Baoding of Hebei province, 071000, China

346591653@163.com

Keywords: Water resources, WDSI model, Grey correlation analysis, Grey prediction

\begin{abstract}
To measure the ability of a region to provide clean water, water demand and supply index (WDSI) is defined as the ratio of water demand and water supply. Obviously, if the index $>1$, the region is suffering from water scarcity. Water demand includes industrial water, agricultural water and domestic water. Water supply consists of surface water, groundwater and other clean water. To evaluate this model, the paper selects six countries in the UN water scarcity map and calculate their WSDI from 1988 to 2002. Then cluster analysis is used to divide the countries. The test result fits water stress indicator interval showed by the UN water scarcity map perfectly.
\end{abstract}

\section{Introduction}

The paper chooses Shandong province as an example for further investigation where water is heavily overloaded. To find the reason for water scarcity, grey correlation analysis is used to search for the prominent factors. The result suggests that surface water, annual precipitation, agricultural water and industrial water affect obviously (their grey relational degree are $0.712,0.651,0.636$, 0.609).

Considering the dynamic nature of the factors, the paper adopt the supply and demand balance theory and $\operatorname{GM}(1,1)$ to predict the development trend of water supply and demand separately. According to the forecast, water shortage in Shandong will be more serious in the next 15 years. Industrial water will increase gradually. Sewage reuse, rainwater harvesting project and water desalination projects will make great progress, which will provide a large proportion of the water supply in the future. Through the analysis, it can be concluded that Shandong will become less vulnerable to the impact of water scarcity. But with the passage of time, the population will be a considerable factor and the amount of clean water is limited. Water will become the key issues in the future.

\section{General Assumptions}

The yield of water provided from desalinization plants and water harvesting techniques will increase according to certain rules.

The industrial, agricultural and domestic water demands are increasing or decreasing exponentially.

The amount of precipitation in Shandong province will wave according to the regulation showed by data from previous years.

The statistical data is accurate.

The region chosen will develop steadily. 


\section{Supply and demand balance analysis theory}

Analysis of Supply and demand balance. Water supply and demand balance analysis, which refers to analyzing the relationship between supply and demand in a certain area for water quantity and water requirement of different periods.

$A W-D E M=\Delta W$

If $\Delta W>0$, the result indicates that the region is able to provide clean water to meet the needs of its population.

If $\Delta W<0$, the result indicates that the region is suffer from water scarcity

If $\Delta W=0$, the result indicates that the region reach the water supply and demand balance

Water supply and demand index consists of two parts: The first part is the water supply model, the second part is region water demand model.

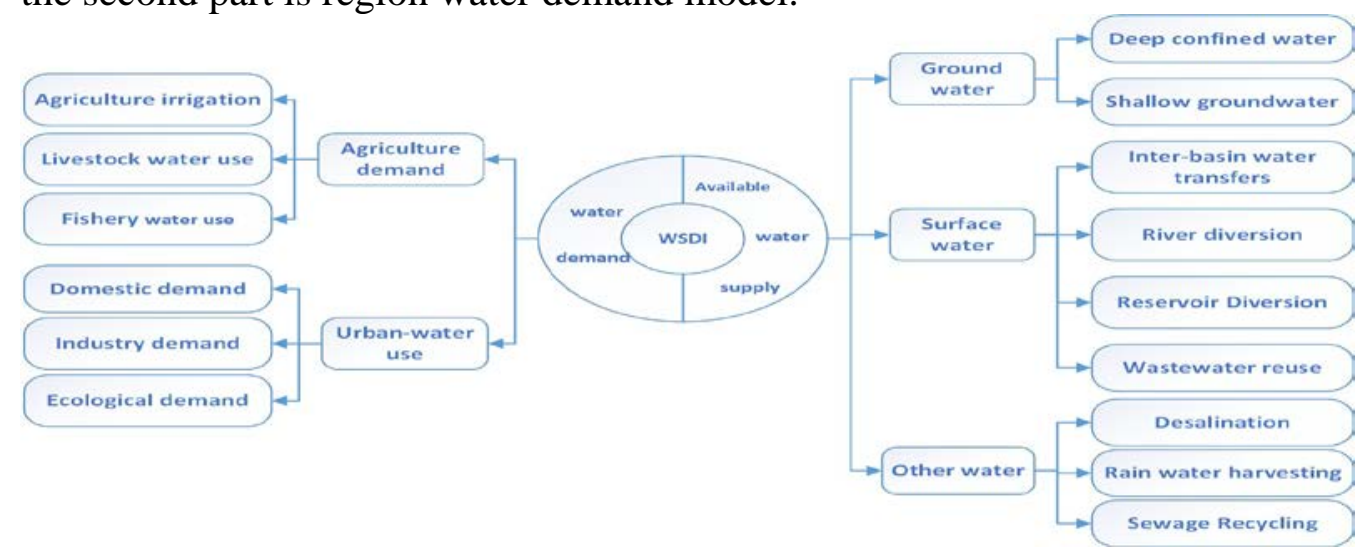

The supply model. Available water by means of water engineering facilities available to meet certain criteria, including surface water, groundwater, inter-basin water transfer, sewage reuse desalination.

The formula of available water supply is:

$$
A W=S w+G w+I w t+S r+D w
$$

Where $A W$ represents available water, $S w$ represents surface water, $G w$ represents groundwater, Iwt represents Inter-Basin Water Transfer, $S r$ represents sewage reuse, $D w$ represents Desalination water.

The Demand Model. Water demand analysis is one of the main elements of supply and demand balance ,including industrial water, agricultural water, domestic water, etc. Since the industrial water sector in different industries vary widely, so industrial water according to industry sectors, statistics and calculated using the water balance method:

$$
Q_{t}=Q_{C}+Q_{d}+Q_{r}
$$

Where $Q_{t}$ - total industrial water consumption ,m3 / a.

$Q_{c}$-industrial water consumption, m3 / a. $\quad Q_{r}$-industrial repeat water consumption,m3 / a

The paper uses the industrial water consumption growth rate over the years to calculate future industrial water consumption, its formula is:

$$
Q_{t i}=Q_{t 0}(1+d)^{n}
$$

Where $Q_{t i}$-Industrial water demand forecast for a year, m3

$Q_{t 0}$ - Industrial water consumption in the beginning , m3;

$\mathrm{d}$-Annual average growth rate of industrial water consumption, $\%$;

$\mathrm{n}$ - The time interval from the start of the year to year that are forecasted. 
The paper uses the per capita living water quota method to calculate the domestic water, it is calculated as: $Q_{\text {life }}=\frac{365 q m}{1000} \quad$ Where $Q_{\text {life }}$-Domestic water, m3 / a. $\quad$ q-Per capita water quota. $\quad \mathrm{m}$-Population that consume water in forecast period.

The annual population can be predicted based on population growth rate.

Agricultural water mainly includes agricultural irrigation, water required by livestock, fishery water and township enterprises water.

$$
Q_{a g r}=Q_{A i}+Q_{L w u}+Q_{F w u}
$$

Where $Q_{A i}$ represents agricultural irrigation. $\quad Q_{L w u}$ represents water required by livestock.

$Q_{F w u}$ represents fishery water

Water demand is calculated as follows: $\quad D E M=Q_{t}+Q_{\text {life }}+Q_{a g r}$

The Water Supply and Demand Index. WSDI can be calculated as follows:

$$
W D S I=\frac{D E M}{A W}
$$

Where $A W$ represents The amount of available water resources

$D E M$ represents Water demand

When $0<W D S I<1$, it indicates that the area has adequate water supply, the smaller the value, the stronger the ability of water supply is.

If $W S D I>1$, it indicates that the water supply in the region is weak, and the larger the value, the more serious water shortages is.

Tests for WSDI. To evaluate the accuracy of the model, the paper takes six countries from the UN water scarcity map as an example. These countries are Australia, Algeria, Egypt, Germany, Libya and Turkey. Their water stress indicators are as follows:

Australia — No water stress Germany—Slightly exploited Turkey—Slightly exploited Algeria— Moderately exploited Egypt-Heavily exploited Libya—over-exploited

The paper collect water resources data of these countries from 1993 to 2002. For each country, the paper get its water demand ( $D E M)$ and total available water ( $A W$ ). Then the paper calculate Water supply and demand index (WSDI ) which is presented as follows:

\begin{tabular}{llll}
\hline Country & WSDI & $(1993-1997)$ & WSDI \\
Germany & 0.448 & 0.388 & \\
Australia & 0.117 & 0.114 \\
Libya & 7.244 & 6.813 \\
Algeria & 0.570 & 0.723 \\
Egypt & 1.185 & 1.383 \\
Turkey & 0.282 & 0.375 \\
\hline
\end{tabular}

Clustering method is applied to divide the countries into 5 classes. Water supply and demand index (WSDI ) of Libya in the past 10 years is much higher than other countries, so Libya can be divided into a class which stands for severe stress for water. Moreover, Germany and Turkey have the similar index during the past 10 years, they can be divided into one class standing for slight stress for water resource. Through comparing the classification, the model is general and effective.

\section{Grey Relational Analysis}

In order to quantitatively describe the connection between the index and the water supply capacity, the paper use Grey Relational Model to analyze the correlation degree between factors and WSDI. Then the paper compares the correlation degree and screen out the main factors.

According to the UN water scarcity map, the paper chooses Shandong, where water is heavily overloaded. Employing the gray correlation analysis, the paper analyzes the physical and economic factors and the Water shortage data from 2005 to 2014. Then the paper finds out the main factors 
affect the water shortage and analyze the relationship between these factors and social and environmental reasons.

First, select a reference sequence: $x_{0}=\left\{x_{0}(k) \backslash k=1,2 \ldots n\right\}=\left(x_{0}(1), x_{0}(2) \ldots, x_{0}(n)\right)$

And the other group of sequence is $\left.x_{i}=\left\{x_{i}(k) \mid k=1,2 \ldots n\right\}\right\}=\left(x_{i}(1), x_{i}(2) \ldots, x_{i}(n)\right), i=1 \ldots m$

Then the correlation degree of $x_{i}$ and $x_{0}$ is: $\quad r_{i}=\frac{1}{n} \sum_{i}^{n} \xi_{i}(k)$

in which $\xi_{i}(k)=\frac{\min _{s} \min _{t}\left|x_{0}(t)-x_{s}(t)\right|+\rho \max _{s} \max _{t}\left|x_{0}(t)-x_{s}(t)\right|}{\left|x_{0}(t)-x_{s}(t)\right|+\rho \max _{s} \max \left|x_{0}(t)-x_{s}(t)\right|}$

The grey relational degree between WSDI and factors are:

Total available water $-0.601 \quad$ Surface water- $0.712 \quad$ Ground Water- 0.638

Annual precipitation-0.651 Agricultural water-0.636 Industrial water-0.609

Domestic water- $0.629 \quad$ Population $-0.572 \quad$ Domestic product -0.490

Sewage treatment rate -0.460

From the above result, it can be concluded that among environmental drivers, total available water and surface water have higher grey correlation degree with WSDI. Among social drivers, industrial water and domestic water have higher grey correlation degree.

\section{Prediction Model}

\subsection{Grey Prediction Model to Predict Water Supply}

In order to forecast the development trend of global and local water supply, the paper not only considers the forecast of total supply, but also considers water supply in each subsystem.

First, using the theory of GM $(1,1)$, the paper predicts total water supply in the next 15 years without consider the subsystems.

Second, the paper forecast the amount of surface water, groundwater, other water in the next 15 years, and then the paper put together three water supply for the total water supply.

Denote the original data sequence by

$x^{(0)}=\left(x^{(0)}(1), x^{(0)}(2), x^{(0)}(3), \ldots x^{(0)}(n)\right)$, where $n$ is the number of years observed.

The AGO formation of $x^{(0)}$ is defined as: $x^{(1)}=\left(x^{(1)}(1), x^{(1)}(2), x^{(1)}(3), \ldots, x^{(1)}(n)\right)$,

Where $x^{(1)}(1)=x^{(0)}(1)$, and $x^{(1)}(k)=\sum_{m=1}^{k} x^{(0)}(m), \quad k=2,3, \ldots n$

The GM(1,1) model can be constructed by establishing a first order differential equation for $x^{(1)}(k)$ as: $\frac{d x^{(1)}(k)}{d k}+a x^{(1)}(k)=b$.

After that, the paper uses the least square methods (LSM) to get the parameter a and $b$ as $u=[a, b]^{T}, Y=\left[x^{(0)}(2), x^{(0)}(3) \ldots x^{(0)}(n)\right]^{T}, B=\left[\begin{array}{cc}-z^{(1)}(2) & 1 \\ -z^{(1)}(3) & 1 \\ \cdot & \cdot \\ \cdot & \cdot \\ \cdot & \cdot \\ -z^{(1)}(n) & 1\end{array}\right] \quad \hat{u}=[\hat{a}, \hat{b}]^{T}=\left(B^{T} B\right)^{-1} B^{T} Y$

The predictive value is: $\quad \hat{x}^{(1)}(k+1)=\left(x^{(0)}(1)-\frac{\hat{b}}{\hat{a}}\right) e^{-\hat{a} k}+\frac{\hat{b}}{\hat{a}}, k=0,1, \ldots, n-1, \ldots$

The prediction results are as follows: 

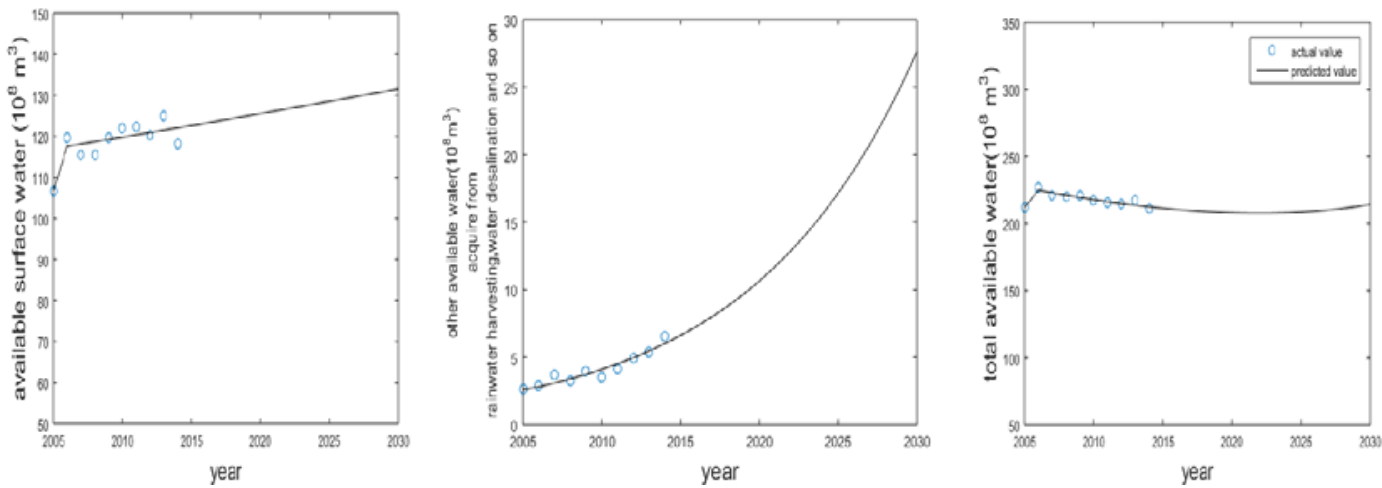

Demand Prediction Model. Industrial water prediction. In 2014, industrial water consumption was 2.864 billion cubic meters. The annual average growth rate of industrial water is $5.4 \%$. Prediction based on the following formula:

$$
Q_{t}=Q_{t 0}(1+d)^{n}
$$

Domestic water. In Shandong, per capita water consumption is 139 liters per day. The number of census in 2010 is 9579.27 ten million, The natural population growth rate is $0.6077 \%$. Prediction based on the following formula:

$$
Q_{\text {life }}=\frac{365 q m}{1000}
$$

Agricultural water. According to the actual situation and statistical data since 2005, with the improvement of the adjustment of agricultural structure and the level of utilization of irrigation, agricultural water demand will decline in an average rate about 0.7 percent. In 2014, the agricultural Consumption is 14.672 billion cubic meters of water. Prediction based on the following formula:

$$
Q_{a g r i}=Q_{a g r}(1-c)^{n}
$$

Further discussion. The paper forecasts available water using data of the quantity of water supply every year in recent 10 years, the result is as Figure 3 shows:

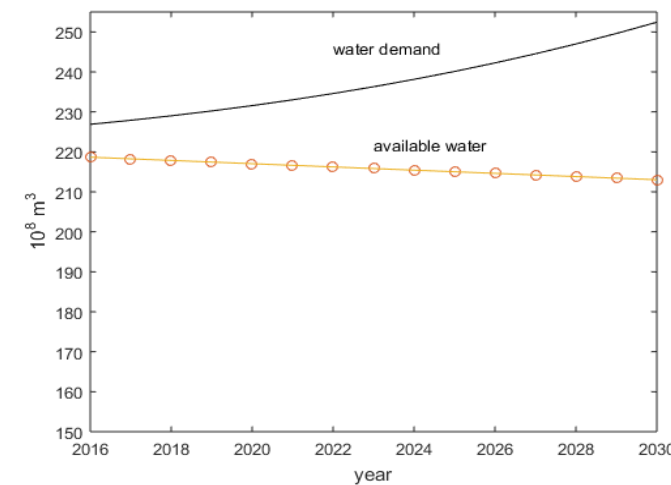

Figure 3

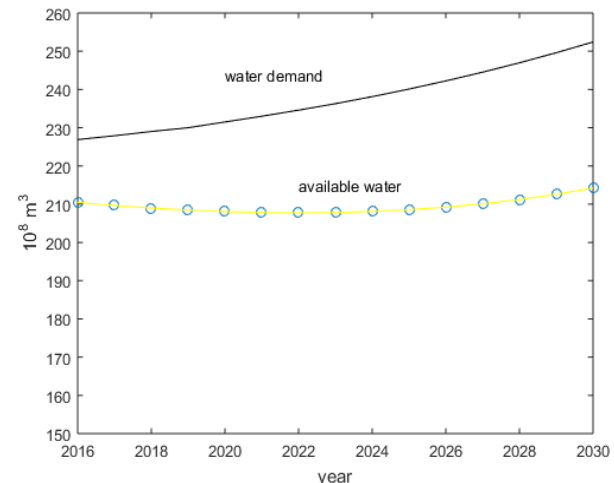

Figure 4

Then the paper predicts components of water supply separately and adds them up. The result is as Figure 4 shows. Comparing the two forecasts, it can be seen that in the next 15 years, the amount of water in sewage treatment and reuse, rainwater harvesting project and desalination projects have made great progress. This reduce the groundwater supply pressure efficiently. However, because of the increasing water demand, especially industrial water, water demand increases in large quantities after 15 years.

The paper conducted a precipitation forecast, the results are as follows: 


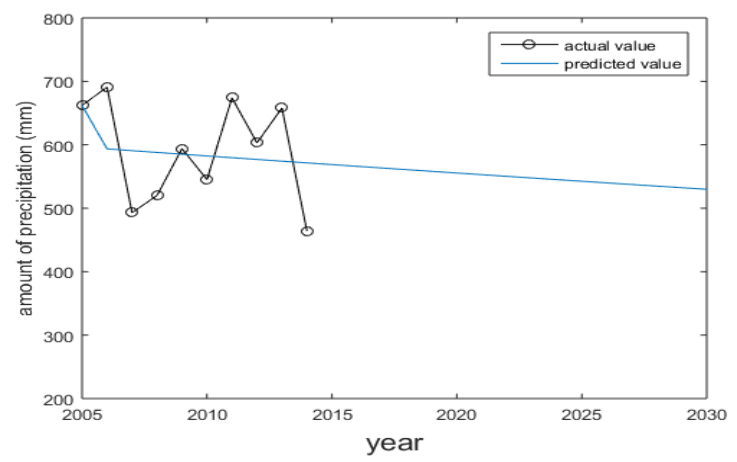

As can be seen from the chart. Precipitation in the next 15 years will be reduced year by year. According to projections, water shortage will reach nearly 40 billion cubic meters of municipal water by 2030. In a word, industrial and agricultural water will be seriously limited.

\section{Conclusion}

1.There are two primary causes for water scarcity: physical scarcity and economic scarcity. Physical scarcity is where there is inadequate water in a region to meet demand. Economic scarcity is where water exists but poor management and lack of infrastructure limits the availability of clean water

2. The quantity of available water will first decrease and then firm up in the future. With the development of relevant technology, water from sewage reuse, rainwater harvesting project, water desalination projects will account for a large proportion of the water supply in the future. Moreover, annual precipitation will influence greatly.

3. Water demand will increase steadily in the future. The growing population and industry will be important factors for water demand.

\section{References}

[1] Oki T, Kanae S. Global hydrological cycles and world water resources[J]. science, 2006, 313(5790): 1068-1072.

[2] Vörösmarty C J, Green P, Salisbury J, et al. Global water resources: vulnerability from climate change and population growth[J]. science, 2000, 289(5477): 284-288.

[3] Viala E. Water for food, water for life a comprehensive assessment of water management in agriculture[J]. Irrigation and Drainage Systems, 2008, 22(1): 127-129.

[4] Hunter, John D. "Matplotlib: A 2D graphics environment." Computing in science and engineering 9.3 (2007): 90-95.

[5] National Bureau of Statistic of China http://data.stats.gov.cn/index.htm

[6] AQUASTAT http://www.fao.org/nr/water/aquastat/water_res/index.stm) 